\title{
Hydrodynamic Analysis of the Miniaturized Hemofilter for a Wearable Ultrafiltration Device
}

\author{
Claudio Ronco ${ }^{a, b}$ Jeong Chul Kim ${ }^{a, b}$, d Francesco Garzotto ${ }^{a, b}$ \\ Daniele Galavotti ${ }^{c}$ Corrado Bellini ${ }^{c}$ Matteo Brolgli ${ }^{c}$ Federico Nalesso ${ }^{a, b}$ \\ ${ }^{a}$ Department of Nephrology, Dialysis and Transplantation, San Bortolo Hospital, and ${ }^{\mathrm{b}}$ International Renal Research \\ Institute Vicenza, Vicenza, and ${ }^{\mathrm{C}}$ R\&D Division, RanD S.r.l., Medolla, Italy; ${ }^{\mathrm{d}}$ Institute of Medical and Biological \\ Engineering, Medical Research Center, Seoul National University, Seoul, South Korea
}

\section{Key Words}

Acute kidney injury · Artificial kidney · Computed

tomography $\cdot$ Extracorporeal dialysis $\cdot$ Heart

decompensation $\cdot$ Hemofiltration $\cdot$ Perfusion

\section{Abstract}

Background/Aims: Using a small wearable hemofiltration device, heart failure (HF) patients may have the possibility of eliminating acute hemodynamic changes and the freedom from spending many hours attached to a large stationary treatment system. Methods: We developed a miniaturized hemofilter for a vest-type wearable ultrafiltration device for the treatment of overhydration and congestive HF. In this study, we investigated the feasibility of the newly developed hemofilter based on dynamic $\mathrm{CT}$ imaging and in vitro evaluation of hydrodynamic properties. Results: The dynamic CT imaging technique showed development of uniform flow distribution and effective bubble removal in the hemofilter. Hydrodynamic performance of the hemofilter was also acceptable with a stable pressure drop in the blood compartment and ultrafiltration profiles in the intended operating ranges for the treatment of congestive HF patients. Conclusions: The newly developed miniaturized hemofilter for a wearable ultrafiltration device meets the technical require- ments of wearable medical devices and its structural design enables uniform blood flow distribution and stable hydrodynamics during operation.

\section{Introduction}

In the US, heart failure (HF) incidence approaches as much as 10 per 1,000 inhabitants $>65$ years of age [1]. Acute decompensated HF and fluid overload are the most common causes of hospitalization in HF patients [2]. Up to $75 \%$ of HF hospitalizations are caused by exacerbations of chronic disease. These are often triggered by nonadherence to sodium and fluid restriction, delayed recognition of signs and symptoms of congestion, worsening underlying renal insufficiency and diuretic resistance. Congestion hastens the progression of HF while its early resolution is associated with improved outcomes [3-5]. Patients with acute decompensated HF are generally treated with intravenous diuretics, which have limited efficacy especially in patients with chronic kidney disease [6], which has spurred an increased interest of the cardiology community in extracorporeal techniques of fluid removal. Conventional renal replacement therapy can be

\section{KARGER}

Fax +4161306 1234

E-Mail karger@karger.com

www.karger.com (c) 2013 S. Karger AG, Basel

0253-5068/13/0353-0127\$38.00/0

Accessible online at:

www.karger.com/bpu
Claudio Ronco, MD

Department of Nephrology, Ospedale San Bortolo

Viale Rodolfi 37

IT-36100 Vicenza (Italy)

E-Mail cronco@goldnet.it 
a treatment option in case of fluid overload in patients refractory to diuretic therapy $[7,8]$. However, current renal replacement therapy requires the use of stationary and bulky devices. Such acute hemofiltration treatments are time consuming (lasting $>4-6 \mathrm{~h}$ ) and they do not provide a steady removal of excess fluid and sodium.

A small wearable device that allows ambulatory hemofiltration to be performed in a slow and continuous fashion could offer patients the possibility of eliminating acute hemodynamic changes and the freedom from spending many hours attached to large stationary ultrafiltration machines, which are currently used for continuous renal replacement therapy. A wearable ultrafiltration device should facilitate prolonged frequent treatment at a low blood flow rate $(<100 \mathrm{ml} / \mathrm{min})$ for more than $12 \mathrm{~h}$ during the patient's daily activities. To be wearable, a hemofiltration unit should be simple and a blood pump control system should be combined with a hemofilter [9]. However, a lower blood flow rate increases membrane contact time, which accelerates blood-membrane interaction; consequently, membrane fouling or cake layers can develop on the surface of the dialysis membrane over long treatment times [10]. Therefore, blood flow distribution in a hemofilter for a wearable ultrafiltration device should be uniform to prevent clotting by hemoconcentration and stagnant flow.

CT imaging techniques are helpful to determine the adequacy of filter design and flow distribution. To analyze blood and dialysate flow distributions in hollow-fiber hemodialyzers, imaging techniques using a CT scanner have been used. Ronco et al. [11] suggested an imaging technique using a helical CT scanner and show effects of flow distributions on solute clearance in hemodialysis. Kim et al. [12] published three-dimensional flow perfusion maps in hollow-fiber hemodialyzers using perfusion CT and visualized flow mismatch between blood and dialysate flow that could lead to a reduction in solute clearance [13]. Additionally, hydraulic flow resistance, pressure drop in the blood compartment and hydraulic permeability are important parameters to decide specifications of hemofilters according to the clinical indication.

Recently, we developed a vest-type wearable ultrafiltration device for the treatment of overhydration and congestive HF, WAKMAN [14]: an easy-to-wear system compatible with daily activities of life, which allows a fully ambulatory treatment. It is equipped with an integrated pump-hemofilter unit, which is extremely compact and lightweight, a unit for the control/monitoring system utilizing wireless communication technology and a rechargeable battery placed in the back. In this study, we
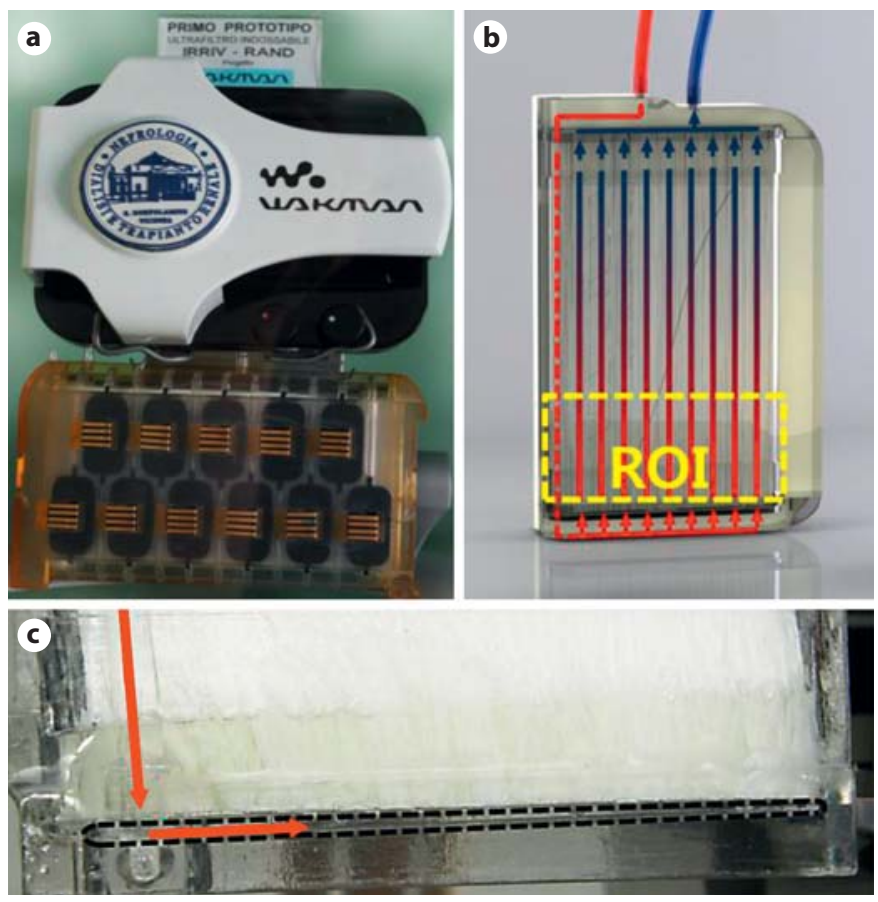

Fig. 1. Integrated design of the miniaturized hemofilter with blood pump system. a Two rows of piezoelectric elements control the rates of blood flow and ultrafiltration. $\mathbf{b}$ A cassette-like hemofilter was designed to be integrated in the pump system; arrows show blood flow direction during the treatment. c The asymmetric structural design of the blood inlet port enhances uniform flow distribution.

evaluated blood flow distribution and hydrodynamic performances of the newly developed hemofilter for a wearable ultrafiltration device, WAKMAN, to investigate the feasibility of the miniaturized hemofilter for fluid-overloaded patients.

\section{Materials and Methods}

The hemofilter of WAKMAN was designed to meet the requirements of a wearable ultrafiltration device (fig. 1). It has a rectangular cuboid shape, to which a pump system can be integrated in a single unit and fitted in the vest pocket (fig. 1a, b). Technical data on the hemofilter are listed in table 1. Blood flows upward from the bottom to the top of the hemofilter to remove bubbles in the blood compartment of the hemofilter during the treatment. The asymmetric structure of the blood inlet port narrowing the gap from the left to the right side was designed to provide tangential and uniform blood flow distribution (fig. 1c). Operating ranges of blood and ultrafiltrate pump rates are 50-60 and $5-6 \mathrm{ml} / \mathrm{min}$, respectively, and these pumps are driven by piezoelectric elements to avoid mechanical damage to blood cells. 
Fig. 2. Cine scanning profiles of the miniaturized hemofilter. Uniform flow distribution develops in the hollow-fiber bundles after an initial phase of stabilization.

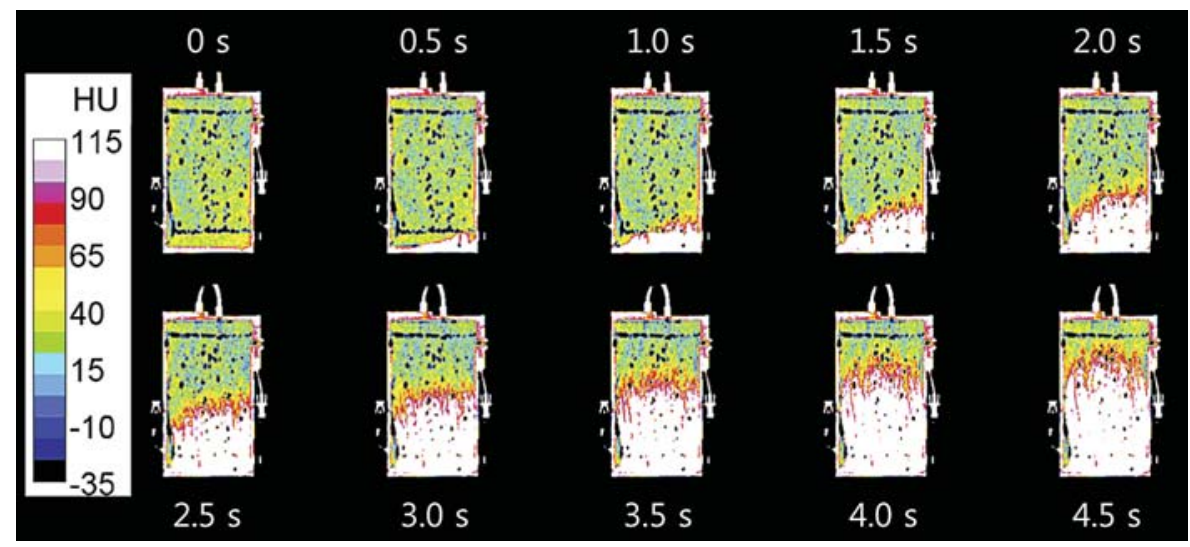

To analyze blood flow distribution in the hemofilter of WAKMAN, after priming blood and dialysate compartments with dialysate, the hemofilter was kept vertically by a support to generate upward blood flow. The dialysate compartment was hermetically closed so that transmembrane flux was not allowed. The scanning procedures were performed in two steps: the topogram for localization and cine scanning. The radiological parameters were as follows: $120 \mathrm{kVp}, 200 \mathrm{~mA}, 512 \times 512$ matrix, $185-\mathrm{mm}$ field of view, 0.5 -s gantry rotation time and $10-\mathrm{mm}$ scan coverage. Cine scanning was performed for 36 cycles supplying $30 \mathrm{ml} / \mathrm{min}$ of solution. The solution was composed of semi-skimmed bovine milk and Iomeron $200^{\circledR}$ (Bracco Diagnostics Inc., Princeton, N.J., USA) with a mixture ratio of 4.0:1.0 to simulate blood-like rheological properties, including a priming phase of the device with standard saline solution. We conducted two types of CT studies: the first was to analyze blood flow distribution under normal operating conditions and the second study was to observe the motion of air bubbles in the hemofilter. For the second study, we intentionally injected $2 \mathrm{ml}$ of air using a 3-way stopcock and a syringe in the arterial line. Using an image processing program (ImageJ, version $1.43 \mathrm{u} ; \mathrm{NIH}$ ), we analyzed blood flow distribution and bubble motion in the hemofilter. For quantitative analysis of perfusion profiles of contrast media with time, we normalized the intensity with the maximum value in the region of interest (ROI, $70 \times 30 \mathrm{~mm}^{2}$ ) defined in figure $1 \mathrm{~b}$.

Hydrodynamic parameters of the hemofilter were measured using normal saline and semi-skimmed milk. Although normal saline and semi-skimmed milk are not able to mimic the nonNewtonian fluid behavior of blood, they are useful for the prediction of hydrodynamic performance and optimization of a hemofilter design in a preliminary step. A pressure drop in the blood compartment according to blood flow rate and effluent pressure was measured to calculate the transmembrane pressure (TMP). The ultrafiltration rate was directly calculated by measuring changes in the weight of the blood bag at 5-min intervals according to blood flow rate. The ultrafiltration coefficient of the hemofilter was calculated from the slope of the ultrafiltration rate TMP curve.

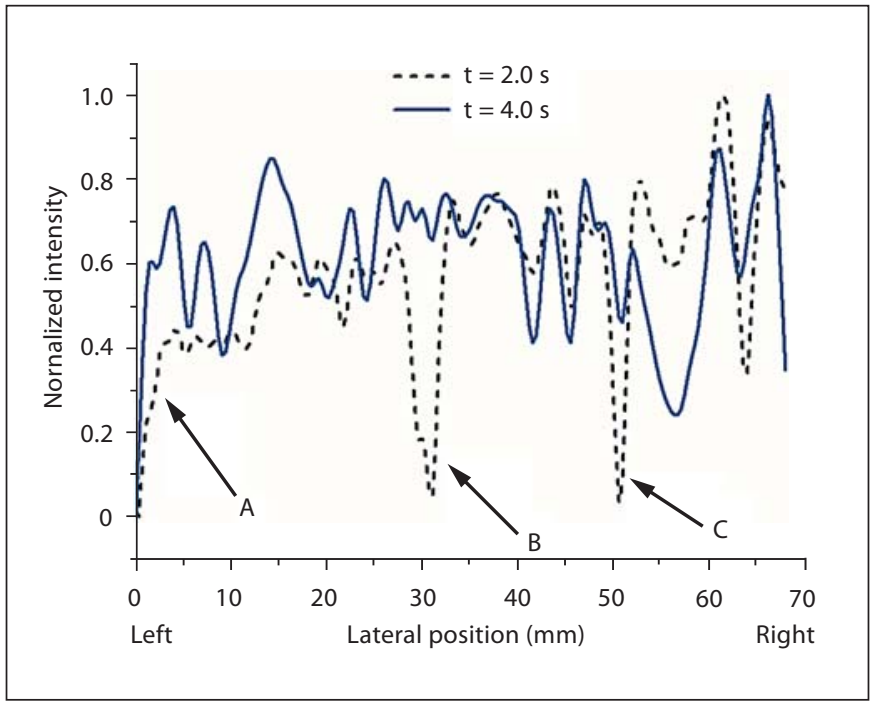

Fig. 3. Normalized intensity profiles during contrast medium perfusion in ROIs of the miniaturized hemofilter.

Table 1. Technical specifications of the miniaturized hemofilter for WAKMAN

Internal fiber diameter

Fiber wall thickness

External fiber diameter

Effective height

Cut-to-cut height

Number of hollow fibers

Effective surface area

Priming volume in hollow-fiber bundle

Total priming volume in the blood compartment
$200 \mu \mathrm{m}$

$30 \mu \mathrm{m}$

$260 \mu \mathrm{m}$

$80 \mathrm{~mm}$

$100 \mathrm{~mm}$

4,600

$0.3006 \mathrm{~m}^{2}$

$14.5 \mathrm{ml}$

$16.8 \mathrm{ml}$ 
Fig. 4. Cine scanning images of the miniaturized hemofilter after injection of air bubbles. Recovery of perfusion and removal of air bubbles are observed during the perfusion of contrast media.

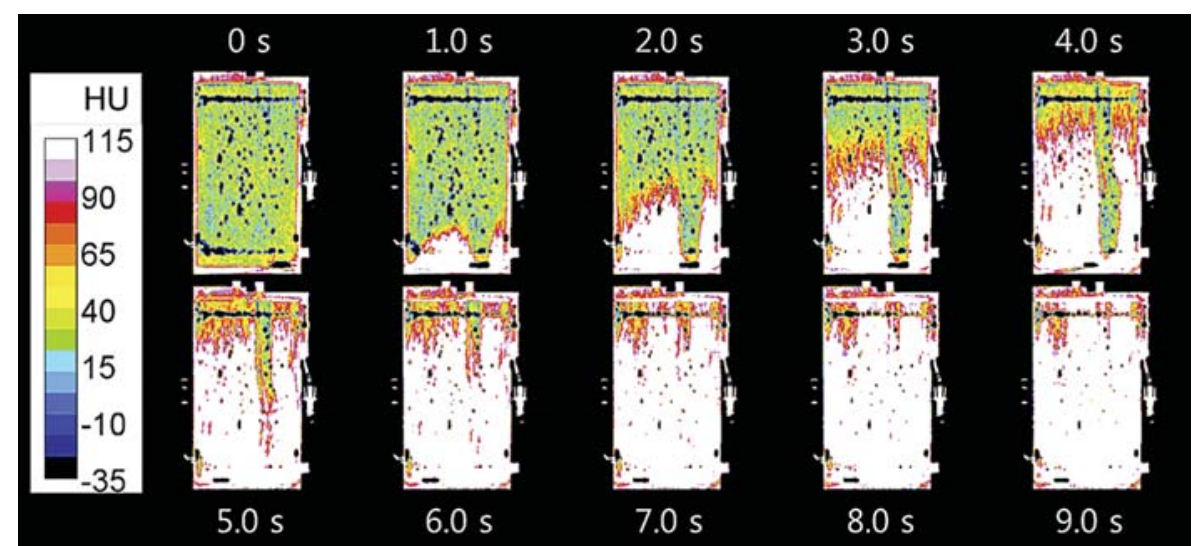

\section{Results}

Figure 2 shows contrast medium perfusion profiles in the hemofilter with time. When contrast media arrived at the blood inlet port of the hemofilter, nonuniform flow distribution was observed for the first $3.0 \mathrm{~s}$, with higher perfusion profiles in the right part of the fiber bundle. However, uniform flow distribution developed after $3.0 \mathrm{~s}$ as contrast media passed the whole hollow-fiber bundle and the perfusion profiles remained uniform until contrast media arrived at the blood outlet port of the hemofilter. Figure 3 shows normalized intensity profiles in ROI with time. At $t=2.0 \mathrm{~s}$, there were some regions where contrast media were not properly perfused in the fiber bundle (A-C). However, as observed in figure 2, flow distributions in these regions recovered to normal values at $\mathrm{t}=4.0 \mathrm{~s}$.

When we intentionally injected air bubbles into the hemofilter, bubbles hindered blood stream flow into the hollow fibers for the first $5 \mathrm{~s}$ (fig. 4). However, as contrast media continued to flow through the fiber bundle, bubble size was reduced and uniform flow developed in the fiber bundle. From the movement of air bubbles from the right to the left part of the fiber bundle, it was possible to predict flow pathlines in the blood inlet indirectly.

Pressure drop in the blood compartment and TMP linearly increased with increasing blood flow rate for both normal saline and semi-skimmed bovine milk (fig. $5 \mathrm{a}, \mathrm{b}$ ) and the calculated ultrafiltration coefficients were 30.03 and $3.17 \mathrm{ml} / \mathrm{h} / \mathrm{mm} \mathrm{Hg}$ for normal saline and semi-skimmed bovine milk, respectively (fig. 5c), in the intended operating ranges of blood flow $(50-60 \mathrm{ml} / \mathrm{min})$ and ultrafiltration rate $(5-6 \mathrm{ml} / \mathrm{min})$ of the wearable ultrafiltration device (WAKMAN).

\section{Discussion}

In this study, we analyzed flow distribution and hydrodynamic performance of the newly developed hemofilter for a wearable ultrafiltration device. A dynamic CT imaging technique showed the development of uniform flow distribution and effective bubble removal in the hemofilter. Hydrodynamic performance of the hemofilter was also acceptable with a stable pressure drop in the blood compartment and ultrafiltration profiles in the intended operating ranges for the treatment of congestive HF patients. Development of uniform flow distribution and effective removal of air bubbles in hollow-fiber bundles of the newly developed hemofilter possibly were affected by the design of the blood inlet port (fig. 1c): tangential injection of the blood stream to the membrane potting and optimal asymmetry of the port enhanced flow distribution. In most hollow-fiber hemodialyzers, the arterial port (inlet cap) is designed to develop a normal blood stream to the surface of fiber potting. However, the modification in the arterial port design to tangential flow injection enhances flow distribution in peripheral regions of hollow-fiber bundles $[11,13]$.

The ultrafiltration coefficient of the newly developed hemofilter was overestimated in the hydrodynamic study with normal saline and underestimated for semi-skimmed milk. According to manufacturer's specifications, the selected membrane material of the hemofilter has an ultrafiltration coefficient of $42 \mathrm{ml} / \mathrm{h} / \mathrm{mm} \mathrm{Hg} / \mathrm{m}^{2}$. In our hydrodynamic study, this value was $9.51 \mathrm{ml} / \mathrm{h} / \mathrm{mm} \mathrm{Hg} / \mathrm{m}^{2}$. Theoretically, according to the international standard, a filtration test should be performed with anticoagulated bovine or human blood with a hematocrit of $32 \%$ and a protein content of $60 \mathrm{~g} / \mathrm{l}$ [15]. The selection of a testing fluid influenced filtration performance of the hemofilter. 


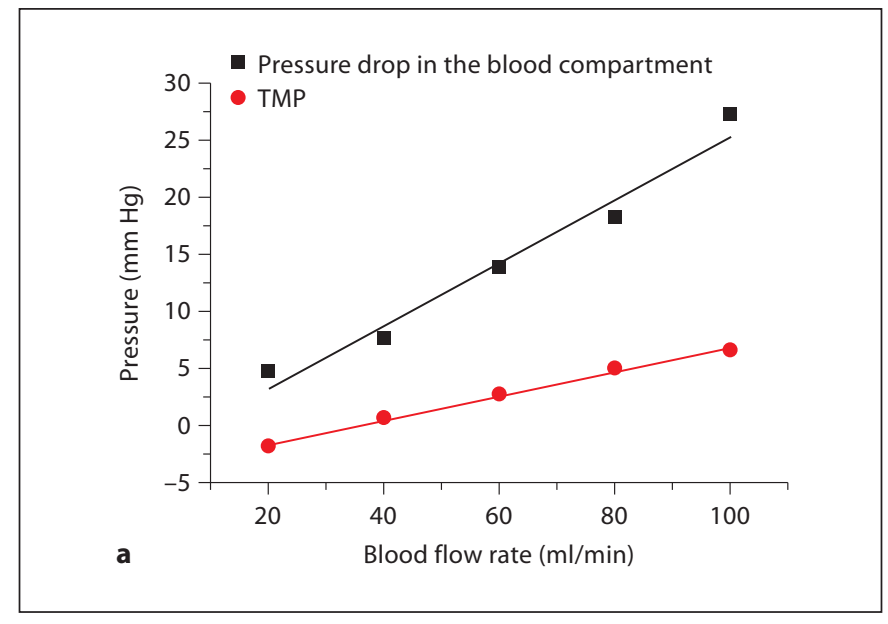

Fig. 5. In vitro test results on hydrodynamic performances of hemofilter with normal saline and semi-skimmed milk. a Experimental results with normal saline. b Experimental results with semi-skimmed milk. c Ultrafiltration rate and transmembrane pressure show a linear relationship for both normal saline and semi-skimmed milk.

In our study with semi-skimmed milk, milk fat and albumin possibly decreases effective membrane pore size despite the high water content compared to blood.

In conclusion, the newly developed miniaturized hemofilter for a wearable ultrafiltration device meets the technical requirements of wearable medical devices and its structural design enables uniform blood flow distribution and stable hydrodynamics during operation. A blood performance test is required to provide information on coagulation properties during the long treatment session for HF patients.
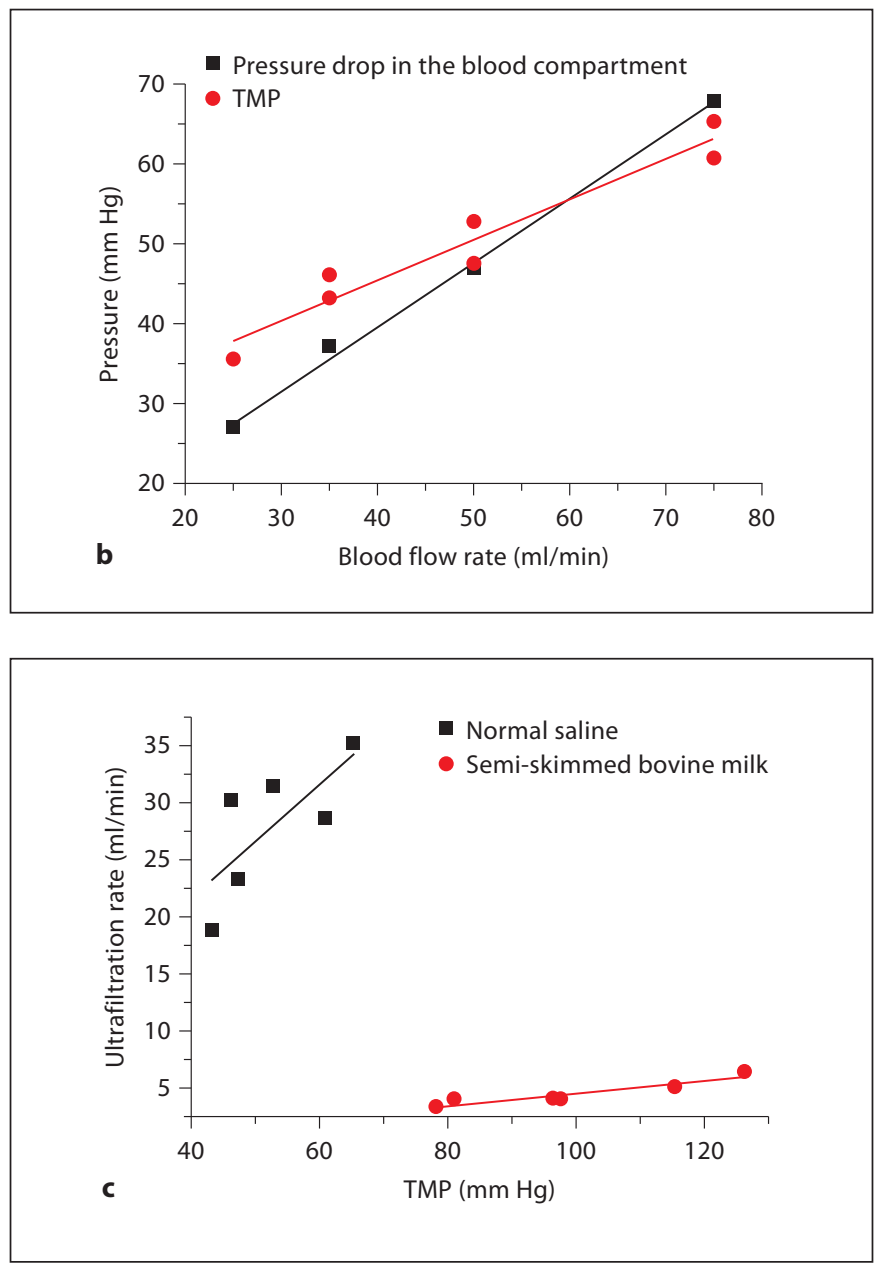

Acknowledgment

This study was supported by a Fondazione Cariverona grant (No. 2010.1087).

\section{Disclosure Statement}

Daniele Galavotti, Corrado Bellini and Matteo Brolgli are employees of RanD S.r.l.; this study is partially supported by RanD S.r.l.

\section{References}

Hemofilter for Wearable Ultrafiltration
Roger VL, Go AS, Lloyd-Jones DM, Adams RJ, Berry JD, Brown TM, Carnethon MR, Dai S, de Simone G, Ford ES, Fox CS, Fullerton HJ, Gillespie C, Greenlund KJ, Hailpern SM, Heit JA, Ho PM, Howard VJ, Kissela BM, Kittner SJ, Lackland DT, Lichtman JH, Lisabeth LD, Makuc DM, Marcus GM, Marelli A, Matchar
DB, McDermott MM, Meigs JB, Moy CS, Mozaffarian D, Mussolino ME, Nichol G, Paynter NP, Rosamond WD, Sorlie PD, Stafford RS, Turan TN, Turner MB, Wong ND, Wylie-Rosett J: Heart disease and stroke statistics - 2011 update: a report from the American Heart Association. Circulation 2011;123:e18-e209. 
2 Costanzo MR, Cozzolino M, Aspromonte N, Mistrorigo F, Valle R, Ronco C: Extracorporeal ultrafiltration in heart failure and cardio-renal syndromes. Semin Nephrol 2012; 32:100-111.

-3 Jain P, Massie BM, Gattis WA, Klein L, Gheorghiade M: Current medical treatment for the exacerbation of chronic heart failure resulting in hospitalization. Am Heart J 2003; 145:S3-S17.

4 Cayley WE Jr: Prognostic importance of elevated jugular venous pressure and a third heart sound in patients with heart failure. $\mathrm{N}$ Engl J Med 2001;345:1912, author reply 1913.

$\checkmark 5$ Androne AS, Katz SD, Lund L, LaManca J, Hudaihed A, Hryniewicz K, Mancini DM: Hemodilution is common in patients with advanced heart failure. Circulation 2003; 107:226-229.

-6 Felker GM, Lee KL, Bull DA, Redfield MM, Stevenson LW, Goldsmith SR, LeWinter MM, Deswal A, Rouleau JL, Ofili EO, Anstrom KJ, Hernandez AF, McNulty SE, Velazquez EJ, Kfoury AG, Chen HH, Givertz
MM, Semigran MJ, Bart BA, Mascette AM, Braunwald E, O'Connor CM: Diuretic strategies in patients with acute decompensated heart failure. N Engl J Med 2011;364:797805.

7 Blake P, Paganini EP: Refractory congestive heart failure: overview and application of extracorporeal ultrafiltration. Adv Ren Replace Ther 1996;3:166-173.

8 Khalifeh N, Vychytil A, Horl WH: The role of peritoneal dialysis in the management of treatment-resistant congestive heart failure: a European perspective. Kidney Int Suppl 2006;103:S72-S75.

-9 Kim JC, Garzotto F, Nalesso F, Cruz D, Kim JH, Kang E, Kim HC, Ronco C: A wearable artificial kidney: technical requirements and potential solutions. Expert Rev Med Devices 2011;8:567-579.

10 Huang Z, Gao D, Letteri JJ, Clark WR: Blood-membrane interactions during dialysis. Semin Dial 2009;22:623-628.

11 Ronco C, Brendolan A, Crepaldi C, Rodighiero M, Scabardi M: Blood and dialysate flow distributions in hollow-fiber hemodialyzers analyzed by computerized helical scanning technique. J Am Soc Nephrol 2002;13(suppl 1):S53-S61.

12 Kim JC, Kim JH, Kim HC, Kim KG, Lee JC, Kang E, Min BG, Ronco C: Three-dimensional dialysate flow analysis in a hollowfiber dialyzer by perfusion computed tomography. Int J Artif Organs 2008;31:553560.

13 Kim JC, Kim JH, Sung J, Kim HC, Kang E, Lee SH, Kim JK, Min BG, Ronco C: Effects of arterial port design on blood flow distribution in hemodialyzers. Blood Purif 2009;28: 260-267.

14 Ronco C, Davenport A, Gura V: The future of the artificial kidney: moving towards wearable and miniaturized devices. Nefrologia 2011;31:9-16.

15 Iso 8637:2004: Cardiovascular implants and extracorporeal systems - haemodialysers, haemodiafilters, haemofilters and haemoconcentrators, 2004. http://www.iso.org/iso/ catalogue_detail.htm?csnumber $=53689$. 